\title{
Is gossip power? The inverse relationships between gossip, power, and likability
}

Article in European Journal of Social Psychology · August 2011

DOI: $10.1002 /$ ejsp. 821

CITATIONS

10

1 author:

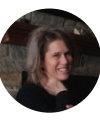

Sally D Farley

University of Baltimore

18 PUBLICATIONS 157 CITATIONS

SEE PROFILE
READS

527

Some of the authors of this publication are also working on these related projects:

Project

Are nonverbal engagement signals or self-reported attitudes better predictors of behavior? View project 


\title{
Fast track report
}

\section{Is gossip power? The inverse relationships between gossip, power, and likability}

\author{
SALLY D. FARLEY* \\ University of Baltimore, Baltimore, USA
}

\section{Abstract}

Despite widespread conjecture regarding the functions and consequences of gossip, little empirical attention has investigated how gossipers are perceived by others. In the present study, 128 individuals were asked to think about a person who either frequently or rarely discussed others while not in their presence. Gender of the target and valence of the gossip were also manipulated. High-frequency gossipers were perceived as less powerful and were liked less than low-frequency gossipers, and those who gossiped negatively were liked less than those who gossiped positively. High-frequency negative gossipers emerged as the least powerful and least likable targets. These results are discussed in relation to the transfer of attitudes recursively effect. Copyright (C) 2011 John Wiley \& Sons, Ltd.

At high school reunions, evaluative talk abounds. Former members of cliques circle up to discuss the successes and failures of their classmates, from who went to medical school or joined the Peace Corps to who had difficulty with the law. The elaboration likelihood model (Petty \& Cacioppo, 1986) has provided some insight into how the sources of these "messages" influence attitudes about the target persons (Briñol \& Petty, 2009). However, less attention has been devoted to how comments made by a source affect the impressions formed of that source. For instance, perhaps Tammy's behavior, which involves whispering to others about Sam's substance abuse problems, is more diagnostic of Tammy than of Sam.

Gossip is defined here as evaluative talk about others while not in their presence (cf. Eder \& Enke, 1991; Foster, 2004). When we hear others gossiping, it prompts attributional processing. We search for the potential motivations and practical implications for relaying the information, and these inform our judgments about the source more so than the target (Wyer, Budesheim, Lambert, \& Swan, 1994). This is especially true of negative evaluative talk, which is weighted more heavily than positive talk (Baumeister, Bratslavsky, Finkenauer, \& Vohs, 2001) because it is perceived to be more diagnostic of personality (Jones \& Davis, 1965) and because it violates our norms of polite conversation (Wyer et al., 1994).

The transfer of attitudes recursively (TAR) effect describes the general tendency for positive or negative information that is relayed by a source to transfer over to the source (Gawronski \& Walther, 2008). Previous research by Folkes and Sears (1977) is consistent with this model. They found greater liking for those who endorsed positive opinions than negative opinions, regardless of whether they expressed opinions about people, objects, or events. Furthermore, this tendency for individuals to "like the likers" surpassed liking due to similarity (Folkes \& Sears, 1977). In another experiment, comments that violated normative expectations were responsible for decreased liking ratings of the source (Wyer et al., 1994). Specifically, observers showed less liking for individuals who commented positively about themselves (thus appearing immodest) and those commenting negatively about those in their presence (thus appearing rude) (Wyer et al., 1994). In addition, in four experiments testing the TAR effect, individuals who gossiped negatively were themselves evaluated negatively, whereas those who gossiped positively were evaluated positively (Gawronski \& Walther, 2008). Gawronski and Walther (2008) invoked a cognitive attributional process to explain these effects-we infer that likers are themselves more likable than are dislikers. Clearly, research shows that gossip valence differentially affects perceptions of likability, but is the TAR effect more global in scope, including other dimensions such as power? A central purpose of the present research is to determine if gossip valence has parallel effects on power and likability or if it has divergent relationships with power and likability. To address these questions, it is necessary to discuss the empirical research on the functions and consequences of gossip.

\section{Gossip Research}

To most laypeople, gossip has a bad reputation. The pages devoted to the subject of gossip in organizational journals affirm the perilous consequences of talking about others behind their backs and advocate strategies to reduce gossip in the workplace (cf. Baker \& Jones, 1996; Lachnit, 2001). Despite the potentially ruinous consequences of gossip (Turner, Mazur, Wendel, \& Winslow, 2003), social psychologists, anthropologists, and 
sociologists have highlighted the myriad of important social functions that gossip serves.

Dunbar (1996, 2004) maintained that gossip replaced grooming as the primary mechanism for social bonding. In this respect, gossip communicates alliances, increases the intimacy of social bonds, and delineates the distinctions between the in-group and the out-group. Gossip is also a particularly effective strategy for detecting free riders. Free riders are individuals who benefit from group living but fail to contribute to the group (Dunbar, 1996, 2004; McAndrew \& Milenkovic, 2002). Other researchers highlight a related between-group function, that of social control, which involves communicating group norms and reinforcing injunctions against norm violators (McAndrew, 2008; McAndrew \& Milenkovic, 2002; McDonald, Putallaz, Grimes, Kupersmidt, \& Coie, 2007).

Other functions of gossip serve more selfish within-group needs. Within groups, individuals are motivated to maintain and enhance their self-esteem (McAndrew, Bell, \& Garcia, 2007; McAndrew \& Milenkovic, 2002; McDonald et al., 2007). Individuals are especially interested in gossip about their friends, family members, and rivals (McAndrew, 2008), but they are selective about the information they choose to relay to others. They are more likely to relay positive information about in-group members and negative information about out-group members (McAndrew et al., 2007). In this way, gossip can be wielded as a weapon-altering the reputations of others in status-enhancing ways.

Consequently, many researchers have postulated an association between gossip and power (cf. Kurland \& Pelled, 2000). Based on a cultural learning perspective of gossip, Baumeister, Zhang, and Vohs (2004) argued that gossip is the means by which cultural norms are transmitted to others. Therefore, gossipers are socially savvy individuals who possess informational power over others (see also Ben-Ze'ev, 1994). Gossipers have been portrayed as the gatekeepers of information, choosing to relay or withhold information about others (Foster \& Rosnow, 2006; Kurland \& Pelled, 2000). For example, Guerin and Miyazaki (2006) noted that the first person to relay important gossip to another earns huge social capital in terms of social influence. It can also be inferred from Dunbar's writings (Dunbar, 1996, 2004) that those who gossip frequently are more influential than those who gossip less, as gossip is the mechanism for keeping abreast of changes in one's social network. According to Dunbar (2004), gossip is "... the core of human social relationships, indeed of society itself" (p. 100), so those on the outskirts of the communication network are in danger of being marginalized.

Despite a resurgence of interest in the functions and consequences of gossip, relatively little empirical attention has been paid to perceptions of those who gossip. If gossip serves to enhance one's status, those who gossip frequently should be perceived as more powerful/higher in status than those who rarely gossip. In fact, researchers determined that sorority girls who gossiped the most emerged as the most influential clique in the sorority, in the center of the communication network (Jaeger, Skleder, Rind, \& Rosnow, 1994). Other research that involved coding episodes of gossip in fourth-grade girls found that popular girls gossiped more than rejected girls (Lansford et al., 2006; McDonald et al., 2007). In another study, sociologists recorded reactions to gossip in lunchroom settings and found that gossip was initiated only by those of medium to high status (Eder \& Enke, 1991). Furthermore, the only people to challenge gossip were those of equal or higher status than the gossipers (Eder \& Enke, 1991). Eder and Enke speculated that lower status individuals were less likely to initiate gossip for fear of being contradicted by higher status individuals. Thus, gossip may be a privilege afforded to those higher on the social hierarchy.

Given this evidence that gossipers are the "movers and shakers" of their communication networks and that they frequently have many friends (Jaeger et al., 1994), one would assume that those who gossip are well liked. However, the little empirical evidence that exists on this topic seems to contradict this logic - those who gossip frequently are rated as less likable than those who gossip less (Farley, Timme, \& Hart, 2010; Jaeger et al., 1994; Turner et al., 2003). In a rare experimental gossip investigation, Turner et al. paired individuals with a friend or a stranger and asked them to initiate a positive or negative comment about the experimenter (compared with control). Regardless of the valence of the gossip, gossipers were assigned lower liking, expertise, and trust ratings than were non-gossipers. Valence did interact with relationship status, but it was the friends who suffered more for gossiping, especially in the negative gossip condition. These results seem to contradict Dunbar's social bonding theory (Dunbar, 1996, 2004), but the content of the gossip may have influenced the outcome. Gossip achieves its power through the communication of socially important information, so commenting negatively about someone outside of one's social network appears petty and small.

The experiment of Turner et al. (2003) does bring to light an important moderator of the perceptions of gossip, which heretofore has received sparse empirical attention-valence. As mentioned above, research testing the TAR effect found that negative gossipers are liked less than positive gossipers (Gawronski \& Walther, 2008). Negative information is more salient and more influential in our judgments than is positive information (Baumeister et al., 2001). Furthermore, from several perspectives (status enhancement, social control, intimacy), negative gossip may be more valuable than positive gossip. Gossiping widely about the sexual infidelities of an enemy acts to increase one's own status (in part through downward social comparison) (Wert \& Salovey, 2004) communicates to others that sexual indiscretion is not acceptable (Foster, 2004) and bonds the gossiper and the gossip recipient more so than does positive gossip (Bosson, Johnson, Niederhoeffer, \& Swann, 2006). A predisposition to be on the lookout for social cheats and potential danger would also call greater attention to negative gossip than positive (Baumeister et al., 2004; Dunbar, 1996, 2004).

How might this greater attentiveness to negative gossip affect the perceptions of the gossiper? Bosson et al. (2006) argued that negative gossip is likely to be perceived as more diagnostic, potentially causing perceptions of negative gossipers to be more extreme than positive gossipers. In addition, when Sally relays negative tidbits about Geoff to Lindsay, Lindsay becomes aware that Sally could possibly betray her own confidences. Thus, negative gossip can increase coercive power (Kurland \& Pelled, 2000) but at the expense of liking (Turner et al., 2003). 
Individuals may want to be associated with gossipers so that they can effectively monitor those in their social networks, but individuals are wary of what gossipers may say to others, especially when they spread negative gossip.

Despite much theoretical speculation about the purposes and consequences of gossip, relatively little empirical attention has been devoted to how gossipers are actually perceived. The few notable exceptions (Farley et al., 2010; Jaeger et al., 1994) failed to take into consideration an important moderator, gossip valence. Although Turner et al. (2003) redresses some of this gap, finding that gossip decreased ratings of liking, trust, and expertise, researchers defined gossip as a positive or negative comment about a stranger. This operationalization may have been germane for experimental control but fails to capture how gossip is communicated in real world settings-we gossip to and about our friends (Foster, 2004). In addition, researchers have postulated an association between gossip and informational power (Ben-Ze'ev, 1994; Foster \& Rosnow, 2006; Kurland \& Pelled, 2000) and other specific types of power as specified by French and Raven (1959) (as outlined by Kurland \& Pelled, 2000), but these associations have yet to be empirically tested.

The present investigation seeks greater understanding as to how gossipers are perceived in terms of power and liking. To better understand how gossipers (and their non-gossiping counterparts) are perceived in real-life settings, an exemplar method was employed. For example, in one condition, participants were asked to think of a woman who spent a lot of time talking negatively about others who were not present and to rate this woman on power and liking dimensions. As a consequence, participants evaluated individuals they knew and presumably had relationships with (as opposed to fictitious characters in vignettes). Rating a known target should have increased experimental realism for the participants, given that individuals are typically highly invested in their social networks. In addition, because we gossip to and about our friends (Foster, 2004), this exemplar method was deemed to have substantially greater ecological validity than the vignette method. Furthermore, to decrease demand characteristics and sensitization to the manipulation, participants believed that the study was about "informal communication" and the word gossip was never utilized.

Although gossip may have complex relationships with different dimensions of power (for example, coercive versus reward, French \& Raven, 1959), this study is intended to shed light on the social influence consequences of gossip. Given that gossip is inherently related to informational power, the following question remains - are those who choose to relay positive/negative information about others perceived as more influential, powerful, and controlling of our behavior than those who do not? The study seeks to determine whether gossiping is possibly perceived as an effective strategy for status enhancement (McAndrew et al., 2007) or if frequent gossipers are perceived negatively because of the TAR effect (Gawronski \& Walther, 2008).

Given the substantial evidence that gossip and power are related, (Ben-Ze'ev, 1994; Eder \& Enke, 1991; Jaeger et al., 1994; Lansford et al., 2006; McDonald et al., 2007), Hypothesis 1 predicted that high-frequency gossipers would be viewed as more powerful than low-frequency gossipers.
Hypothesis 2 predicted that this increase in power would come at the expense of liking, as high-frequency gossipers would be perceived as less trustworthy and consequently less likable than low-frequency gossipers (Turner et al., 2003). Because of the greater import and weight of negative gossip (Baumeister et al., 2001; Dunbar, 1996, 2004) and because of the predictions of TAR, it was also hypothesized (Hypothesis 3) that negative gossipers would be perceived as less likable than positive gossipers. Finally, Hypothesis 4 predicted that gossip valence and gossip frequency would interact such that highfrequency negative gossipers will be perceived as the least likable targets. The power implications for positive versus negative gossips remain unclear. Although Kurland and Pelled (2000) predicted that positive gossip would increase reward power and negative gossip would increase coercive power, the present study operationalized power in terms of social power or influence. Because of the logic of the TAR effect, it was predicted that negative gossipers would be perceived as less powerful than positive gossipers.

\section{METHOD}

\section{Participants}

The study included a total of 128 research participants, who were randomly assigned to one of eight conditions (sample size ranged from 14 to 17 per condition). The majority of the participants $(n=122)$ were students from the University of Baltimore and Albright College who completed the study in return for extra credit in their courses. The remaining six participants were volunteers. The sample was composed of 101 women and 27 men and was fairly ethnically diverse (72 non-Hispanic Caucasians, 46 African-Americans, 5 Asians, and 5 Hispanic or multiple race). The participants' ages ranged from 18 to 59 , with a mean age of 25.64. Approximately half of the participants $(n=62)$ completed the study by accessing a link posted on a research participation system (Sona), and half $(n=66)$ completed the surveys on paper in quiet classroom settings.

\section{Design}

The researcher randomly assigned participants to conditions using a 2 (target gender) $\times 2$ (tendency to gossip: high versus low) $\times 2$ (valence: positive or negative) between-subjects factorial design with power and liking as dependent measures. The Sona participants were randomized to condition via birth month (for example, 1 January-15 February were assigned to condition one). For those completing the questionnaire in classroom settings, randomization was ensured by shuffling packets.

\section{Materials}

Participants completed one questionnaire designed to assess perceived liking and power of the target individual and Nevo, Nevo, and Derech-Zehavi's (1994) tendency to gossip questionnaire, which assesses an individual's self-reported tendency to gossip. Liking was measured using Rubin's (1970) 13-item liking scale, which showed strong internal consistency in this 
study $(\alpha=.93)$ and good discriminant validity in Rubin's research. This scale was selected because it captures global likability (degree of positive evaluation), but it also taps into perceived similarity/oneness, a dimension that was expected to differentiate positive and negative gossipers. The researcher constructed a five-item social power scale to capture the extent to which an individual felt influenced by and controlled by the target (e.g., _ is very influential) $(\alpha=.75)$. Twenty-two other items were included in the questionnaire as distracters (e.g., _ is very active and _ is very inconsistent).

The tendency to gossip questionnaire created by Nevo et al. (1994) is a 20-item scale designed to assess the dispositional propensity for individuals to gossip with others. For example, participants indicated their level of agreement with items such as "I like to tell friends about interesting details concerning other people" (Nevo et al., 1994, p. 192). The scale was found to be highly reliable with two different samples in the research of Nevo et al. In addition, peer ratings of gossip behavior correlated highly with self-report ratings, establishing strong validity (Nevo et al., 1994). Cronbach's alpha for tendency to gossip was .86 in the present study.

\section{Procedure}

Participants were asked to think of a person who possessed the attributes according to condition and then to use the scale items to rate the target individual. Target gender was operationalized simply as "think of a man" or "think of a woman". High tendency to gossip individuals were those that "spent a lot of time talking about other people when they (were) not around" whereas low tendency individuals "spent little time talking about other individuals when they (were) not around". Valence was operationally specified as either "saying negative things about (others)" or "saying positive things about others".

Participants were told that the study was about "Informal Communication". After the instructional manipulation, participants completed the social power and liking items, which were mixed in among the distracter items in a random manner. Participants completed the tendency to gossip questionnaire last to decrease sensitization to the manipulation.

\section{RESULTS}

Cronbach's alphas for all three scales (reported above) exceeded traditional standards of internal consistency, so the items were summed for each scale to create a single index. Although the liking and power scales were designed to measure unique constructs, they were significantly positively correlated in this study $(r=.63, p<.001)$, a point which is elaborated upon in the discussion. Because it seems reasonable to assume that participants with a high tendency to gossip would evaluate others differently than those with a low tendency to gossip (Turner et al., 2003), the researcher included participants' tendency to gossip as a covariate. The tendency to gossip covariate failed to achieve statistical significance for either social power or liking in ANCOVAs, so the analyses reported are $2 \times 2 \times 2$ ANOVAs. No main effects or interactions with target gender were obtained for either dependent measure, so target gender is not discussed.
With regard to social power, although the main effects for gossip frequency and gossip valence were significant, they were qualified by a significant frequency by valence interaction, $F(1,120)=5.29, p=.02, \eta_{\mathrm{p}}{ }^{2}=0.04$. When gossip frequency was low, valence did not affect power, $t(61)=-0.36$, $p=.72$, but when gossip frequency was high, positive gossipers were perceived as significantly more powerful than negative gossipers, $t(63)=-3.86, p<.001$ (see Table 1 for the descriptive statistics for social power). In addition, targets who gossiped positively were perceived as more powerful than targets who gossiped negatively, $F(1,120)=8.28, p=.005$, $\eta_{\mathrm{p}}{ }^{2}=0.07$. Contrary to Hypothesis 1 , high-frequency gossipers were perceived as less powerful than low-frequency gossipers, $F(1,120)=5.69, p=.02, \eta_{\mathrm{p}}{ }^{2}=0.05$.

The $2 \times 2 \times 2$ ANOVA yielded significant main effects for gossip frequency and gossip valence on liking, but these main effects were also qualified by a significant gossip frequency by gossip valence interaction, $F(1,119)=6.84, p=.01, \eta_{\mathrm{p}}{ }^{2}=$ 0.05 . When gossip frequency was low, valence did not affect liking ratings, $t(60)=-1.11, p=.27$, but when gossip frequency was high, positive gossipers were liked significantly more than negative gossipers, $t(63)=-4.81, p<.001$ (see Table 2 for descriptive statistics for liking). The main effect for gossip frequency was significant such that targets who frequently gossiped were liked less than targets who gossiped rarely, $F(1,119)=7.11, p=.009, \eta_{\mathrm{p}}{ }^{2}=0.06$. The main effect for gossip valence was also significant such that targets who gossiped positively were rated as more likable than those who gossiped negatively, $F(1,119)=16.36, p<.001, \eta_{\mathrm{p}}{ }^{2}=0.12$.

\section{DISCUSSION}

The results provided mixed support for the hypotheses. The predictions pertaining to liking were fully supported. Highfrequency gossipers were liked significantly less than lowfrequency gossipers, in support of Hypothesis 2, and negative

Table 1. Mean power ratings as a function of gossip valence and gossip frequency

\begin{tabular}{lccccc}
\hline & \multicolumn{4}{c}{ Gossip frequency } \\
\cline { 2 - 4 } \cline { 5 - 6 } Gossip valence & $M$ & $S D$ & & \multicolumn{2}{c}{ Low } \\
\cline { 2 - 6 } \cline { 5 - 6 } Hositive & 15.97 & 3.02 & & 16.02 & 3.31 \\
Negative & 12.85 & 3.58 & & 15.68 & 3.59 \\
\hline
\end{tabular}

Table 2. Mean liking ratings as a function of gossip valence and gossip frequency

\begin{tabular}{lcrrrr}
\hline & \multicolumn{4}{c}{ Gossip frequency } \\
\cline { 2 - 3 } & \multicolumn{2}{c}{ High } & & \multicolumn{2}{c}{ Low } \\
\cline { 2 - 3 } \cline { 5 - 6 } Gossip valence & $M$ & $S D$ & & $M$ & $S D$ \\
\hline Positive & 48.44 & 8.37 & & 48.63 & 8.27 \\
Negative & 37.09 & 10.59 & & 46.03 & 10.08 \\
\hline
\end{tabular}


gossipers were liked less than positive gossipers, in support of Hypothesis 3. Furthermore, Hypothesis 4 was confirmed such that the high-frequency negative gossipers emerged as the least likable targets. Despite the tendency for individuals with a high propensity to gossip to have many friends, they have also emerged in the literature as not especially well liked or warm (Farley et al., 2010; Jaeger et al., 1994). Perhaps high gossipers are individuals who we welcome into our social networks for fear of losing the opportunity to learn information, but we tend to keep them at arm's length.

Despite the notion that gossip is a mechanism for status enhancement, the results from this study show that highfrequency gossipers (especially those who gossip negatively) were not perceived as having more social power. Rather, contrary to Hypothesis 1, high-frequency gossipers were perceived as less powerful than low-frequency gossipers. In addition, high-frequency negative gossipers emerged as the least powerful targets in the study. These results are consistent with the TAR effect (Gawronski \& Walther, 2008). Although the TAR effect has heretofore demonstrated decreased liking for negative evaluators, the present research offers evidence that this "negative halo" may extend beyond likability. Additional evidence for this "negative halo" is that, despite the fact that the liking and power scales were measuring quite different constructs, the dimensions were significantly positively correlated in this study. Negative gossipers were simply viewed negatively, regardless of dimension.

Another explanation for this pattern of results is that the relationship between gossip and social power is likely curvilinear. Individuals may be at the low end of the gossiping spectrum because they are not socially attuned (Ben-Ze'ev, 1994), because they have been marginalized from the social network (Foster, 2004; Levin \& Arluke, 1987), or because they have been deemed untrustworthy (McAndrew, 2008). Although it remains unclear whether refraining from gossip causes one to be socially marginalized or being marginalized restricts one's access to gossip, what is clear is that these individuals are likely to suffer in terms of perceived social power. At the other end of the spectrum, individuals who gossip very frequently may be perceived as indiscriminate, unselective, and untrustworthy (Foster, 2004; Kurland \& Pelled, 2000; McAndrew, 2008) and ultimately lose status (Levin \& Arluke, 1987). Successful status enhancement likely involves using gossip selectively (Foster, 2004; McAndrew, 2008), revealing information to others at moderate levels. The present study prompted participants to attend to gossipers at the high and low levels, which may have failed to capture the curvilinear relationship between gossip and social power.

Furthermore, the nature of the methodology (asking individuals to generate examples of high or low-frequency gossipers) is likely to have resulted in more accessible and consequently more extreme examples. This may be especially true of negative gossipers, who may be asymmetrically extreme because of the greater attention that negative information receives (Baumeister et al., 2001; Bosson et al., 2006).

Valence, which has been neglected in a great deal of gossip research, emerged as an important moderator of the perceptions of gossipers. High-frequency negative gossipers were rated as the least socially powerful and least likable targets. One reason why negative gossip could have been so detrimental to ratings relates to a finding by McAndrew et al. (2007) that we gossip negatively about out-groups and positively about in-groups. Because of the in-group bias, the positive gossip condition is likely to activate thoughts about an in-group member, whereas the negative gossip condition may make one think about an out-group member. The higher liking and social power ratings assigned to positive gossipers may be an artifact of the methodology. However, methods allowing for greater experimental control would likely have sacrificed ecological validity.

Despite the shortcomings of the present study, it represents one of a few empirical investigations into how gossipers are perceived by others. Future research should consider other important moderators of gossip such as inclusion in the gossip, topic of the gossip, and motivations for gossip (groupserving versus self-serving).

\section{ACKNOWLEDGEMENTS}

The author would like to thank Tom Mitchell and Kristen Eyssell for their helpful comments on previous versions of this manuscript.

\section{REFERENCES}

Baker, J. S., \& Jones, M. A. (1996). The poison grapevine: How destructive are gossip and rumor in the workplace. Human Resource Development Quarterly, 7, 75-86.

Baumeister, R., Bratslavsky, E., Finkenauer, C., \& Vohs, K. (2001). Bad is stronger than good. Review of General Psychology, 5(4), 323-370. DOI: 10.1037/1089-2680.5.4.323

Baumeister, R. F., Zhang, L., \& Vohs, K. D. (2004). Gossip as cultural learning. Review of General Psychology, 8, 111-121. DOI: 10.1037/10892680.8.2.111

Ben-Ze'ev, A. (1994). The vindication of gossip. In R. F. Goodman \& A. Ben-Ze'ev (Eds.), Good gossip (pp. 11-24). Lawrence, KS: University Press of Kansas.

Bosson, J. K., Johnson, A. B., Niederhoeffer, K., \& Swann, W. B. (2006). Interpersonal chemistry through negativity: Bonding by sharing negative attitudes about others. Personal Relationships, 13, 135-150.

Briñol, P., \& Petty, R. (2009). Source factors in persuasion: A self-validation approach. European Review of Social Psychology, 20, 49-96. DOI: 10.1080/10463280802643640

Dunbar, R. (1996). Grooming, gossip, and the evolution of language. Cambridge, MA: Harvard University Press.

Dunbar, R. I. M. (2004). Gossip in evolutionary perspective. Review of General Psychology, 8, 100-110. DOI: 10.1037/1089-2680.8.2.100

Eder, D. \& Enke, J. L. (1991). The structure of gossip: Opportunities and constraints on collective expression among adolescents. American Sociological Review, 56, 494-508. DOI: 10.2307/2096270

Farley, S. D., Timme, D., \& Hart, J. W. (2010). On coffee talk and break-room chatter: Perceptions of women who gossip in the workplace. The Journal of Social Psychology, 150(4), 361-368. DOI: 10.1080/00224540903365430

Folkes, V. S., \& Sears, D. O. (1977). Does everybody like a liker? Journal of Experimental Social Psychology, 13, 505-519.

Foster, E. K. (2004). Research on gossip: Taxonomy, methods, and future directions. Review of General Psychology, 8, 78-99. DOI: 10.1037/10892680.8.2.78

Foster, E. K., \& Rosnow, R. L. (2006). Gossip and network relationships. In D. C. Kirkpatrick, S. W. Duck, \& M. K. Foley (Eds.), Relating difficulty: The processes of constructing and managing difficult interaction (pp. 161-180). Mahwah, NJ: Erlbaum.

French, Jr., J. R. P., \& Raven, B. H. (1959). The bases of social power. In D. Cartwright (Ed.), Studies in social power (pp. 150-167). Ann Arbor: University of Michigan Press.

Gawronski, B., \& Walther, E. (2008). The TAR effect: When the ones who dislike become the ones who are disliked. Personality and Social Psychology Bulletin, 34(9), 1276-1289. DOI: 10.1177/0146167208318952 
Guerin, B., \& Miyazaki, Y. (2006). Analyzing rumors, gossip, and urban legends through their conversational properties. The Psychological Record, 56, 23-34.

Jaeger, M., Skleder, A., Rind, B., \& Rosnow, R. (1994). Gossip, gossipers, gossipees. In Good gossip (pp. 154-168). Lawrence, KS: University Press of Kansas.

Jones, E. E., \& Davis, K. E. (1965). From acts to dispositions: The attribution process in person perception. Advances in Experimental Psychology, 2, $1-24$.

Kurland, N., \& Pelled, L. (2000). Passing the word: Toward a model of gossip and power in the workplace. Academy of Management. Academy of Management Review, 25(2), 428-438. DOI: 10.2307/259023

Lachnit, C. (2001). Giving up gossip. Workforce, 80(7), 8.

Lansford, J., Putallaz, M., Grimes, C., Schiro-Osman, K., Kupersmidt, J., \& Coie, J. (2006). Perceptions of friendship quality and observed behaviors with friends: How do sociometrically rejected, average, and popular girls differ? Merrill-Palmer Quarterly: Journal of Developmental Psychology, 52(4), 694-720. DOI: 10.1353/mpq.2006.0036

Levin, J., \& Arluke, A. (1987). Gossip: The inside scoop. New York, NY: Plenum Press.

McAndrew, F. T. (2008). Can gossip be good? Scientific American Mind, 19(5), 26-33.

McAndrew, F. T., Bell, E. K., \& Garcia, C. M. (2007). Who do we tell and whom do we tell on? Gossip as a strategy for status enhancement. The Journal of Applied Psychology, 37(7), 1562-1577. DOI: 10.1111/j.15591816.2007.00227.x
McAndrew, F. T., \& Milenkovic, M. A. (2002). Of tabloids and family secrets: the evolutionary psychology of gossip. Journal of Applied Social Psychology, 32(5), 1064-1082. DOI: 10.1111/j.1559-1816.2002.tb00256.x

McDonald, K., Putallaz, M., Grimes, C., Kupersmidt, J., \& Coie, J. (2007). Girl talk: Gossip, friendship, and sociometric status. Merrill-Palmer Quarterly: Journal of Developmental Psychology, 53(3), 381-411. DOI: 10.1353/mpq.2007.0017

Nevo, O., Nevo, B., \& Derech-Zehavi, A. (1994). The tendency of gossip as a psychological disposition: Constructing a measure and validating it. In Good gossip (pp. 180-189). Lawrence, KS: University Press of Kansas.

Petty, R. E., \& Cacioppo, J. T. (1986). Communication and persuasion: Central and peripheral routes to attitude change. New York: SpringerVerlag.

Rubin, Z. (1970). Measurement of romantic love. Journal of Personality and Social Psychology, 16, 265-273.

Turner, M. M., Mazur, M. A., Wendel, N., \& Winslow, R. (2003). Relational ruin or social glue? The joint effect of relationship type and gossip valence on liking, trust, and expertise. Communication Monographs, 70(2), 129-141. DOI: 10.1080/0363775032000133782

Wert, S. R., \& Salovey, P. (2004). A social comparison account of gossip. Review of General Psychology, 8, 122-137. DOI: 10.1348/ $000712605 \times 85871$

Wyer, R., Budesheim, T., Lambert, A., \& Swan, S. (1994). Person memory and judgment: Pragmatic influences on impressions formed in a social context. Journal of Personality and Social Psychology, 66(2), 254-267. DOI: $10.1037 / 0022-3514.66 .2 .254$ 